\title{
Chemisorption Studies of Promoted Solid-State HDS Catalysts
}

\author{
Jim Lindner, ${ }^{1}$ Amit Sachdev, ${ }^{2}$ Johannes Schwank, \\ and Maria Villa-Garcia ${ }^{3}$ \\ Department of Chemical Engineering, The University of Michigan, \\ Ann Arbor, Michigan 48109-2136
}

Received July 25, 1991; revised January 22, 1992

\begin{abstract}
Oxygen pulse chemisorption measurements were made on a series of model HDS catalysts synthesized from solid-state reactions of elemental starting materials. Three different promoter atoms having the following catalyst stoichiometries were used in this study: $\mathrm{P}_{2 x} \mathrm{Mo}_{1-x} \mathrm{~S}_{2}$ for the Co and $\mathrm{Fe}$ samples and $\mathrm{P}_{x} \mathrm{Mo}_{1, x} \mathrm{~S}_{2}$ for the Ni series. Four samples from each promoter family were studied and the $\mathrm{P} /(\mathrm{P}+\mathrm{Mo})$ weight percent ratio varied from 0.030 to 0.355 . All catalysts displayed Arrhenius type behavior in the HDS of thiophene and it was found that $\mathrm{O}_{2}$ chemisorption uptakes could be correlated with the HDS activity of these solid-state model catalysts. Pulse chemisorption experiments revealed that the more active samples adsorbed increased amounts of $\mathrm{O}_{2}$; hence activity normalizations using $\mathrm{O}_{2}$ uptake resulted in a consolidation of the Arrhenius plots so that the individual data points merged into a narrow band on the plot. Oxygen activity normalizations also revealed that on a per mole of $\mathrm{O}_{2}$ basis, the model catalysts gave thiophene HDS turnover frequencies similar to those found on an industrial HDS catalyst. CO chemisorption experiments were run on a select number of samples and similar trends were observed. 1992 Academic Press, Inc.
\end{abstract}

\section{INTRODUCTION}

Attempts have been made using various probe molecules to correlate the adsorptive capacity of HDS catalysts with the observed catalytic activities. Among the different gases that have been used in these investigations, $\mathrm{O}_{2}, \mathrm{NO}, \mathrm{CO}$, and $\mathrm{H}_{2}$ have demonstrated the ability to selectively titrate the edge sites of the $\mathrm{MoS}_{2}$ structure. Since the edge of the $\mathrm{MoS}_{2}$ crystal has been recognized by many researchers to be linked to HDS activity, these adsorption studies have provided useful information allowing correlations between adsorptive uptake and catalytic activity to be drawn

\footnotetext{
${ }^{1}$ Present address: U.S. Environmental Protection Agency Motor Vehicle Emissions Laboratory, 2565 Plymouth Rd., Ann Arbor, MI 48105.

2 Present address: Dept. of Chemical Engineering, University of Illinois, Urbana, IL 61801.

${ }^{3}$ Present address: Dpto. Química Organometálica, Facultad de Química, Universidad de Oviedo, Oviedo33071, Spain.
}

$(I-5)$. More specifically, $\mathrm{O}_{2}$ pulse chemisorption uptake has been shown to vary linearly with HDS activity for both unsupported $\mathrm{MoS}_{2}(6)$ and sulfided $\mathrm{Ni} / \mathrm{Al}_{2} \mathrm{O}_{3}(7)$ catalysts. This raised the possibility of establishing chemisorption as a faster activity screening technique than actual activity measurements; however, other researchers began to have doubts about the validity of this adsorption-activity correlation. Zmierczak et al. (8) found that $\mathrm{O}_{2}$ chemisorption did not correlate with HDS activity and concluded that their adsorption data reflected the general state of dispersion of the active Mo phase rather than specifically titrating the active centers. Interestingly, they found that $\mathrm{O}_{2}$ capacity increased at higher temperatures, which was interpreted as a slow oxidation or corrosive process proceeding on the catalyst's surface. Because of this phenomenon, these workers did not endorse any activity-adsorption correlation. Similar oxidation of unsupported $\mathrm{MoS}_{2}$ during the chemisorption pro- 
cess has been reported by Daage and Chianelli (9). Yet, despite the reservations raised by these two reports, $\mathrm{O}_{2}$ chemisorption is still used by many laboratories to gain insight into the relationship between the HDS catalyst surface and its corresponding activity (10-13).

Other workers have attempted to use $\mathrm{CO}$ as the adsorbent molecule in order to avoid the problem of surface oxidation $(14,15)$; however, the number of studies employing $\mathrm{CO}$ is not nearly as high. Furthermore, the extent of $\mathrm{CO}$ average on the catalyst is still being debated. In addition to this, $\mathrm{CO}$ adsorbs much more slowly than $\mathrm{O}_{2}$; and, consequently, the $\mathrm{CO}$ peaks detected in the pulse method tend to be very broad with less well-defined endpoints than those characteristically seen in $\mathrm{O}_{2}$ measurements (13). In spite of this problem, $\mathrm{CO}$ adsorption has been shown to correlate with HDS trends $(14,15)$.

This paper reports the results of chemisorption studies on model solid-state HDS catalysts promoted with various group VIII metals. In earlier work on these catalysts $(16-18)$, it appeared that the main role of the promoter atoms was to scavenge sulfur during catalyst synthesis, thereby facilitating the creation of nonstoichiometric molybdenum sulfide phases with enhanced HDS activity. Other hypotheses have been proposed in the literature to explain the role of promoters in HDS catalysis, including the monolayer model (19-21), the intercalation model $(22,23)$, the contact synergy model (24-26), and the CoMoS model $(27,28)$. At present the CoMoS model has become widely accepted, although the exact nature of the active sites is still an open question. In more recent work $(29-31)$ it was even postulated that the active site for HDS may actually be the Co promoter itself and that the molybdenum sulfide phase serves primarily as a secondary support.

In the present work, the objectives are to first establish if the novel solid-state materials followed adsorption patterns for oxygen and CO similar to those seen with tradition- ally prepared HDS catalysts and then, as in the investigations cited earlier, to determine if their respective chemisorption properties could be linked to catalytic activity. Four samples were selected from each promoter family, and within each group two samples had low promoter loadings while two others had high promoter loadings. Experiments were also preformed on the industrial HDS catalyst Katalco to compare our model compounds with an industrial catalyst and to see to what extent meaningful activity normalizations can be made based on adsorptive uptake rather than simply the molybdenum content.

\section{EXPERIMENTAL}

The solid-state catalysts were prepared by combining elemental Mo, S, and promoter atom in the desired stoichiometric amounts, evacuating to $0.1 \mathrm{~Pa}$ in a quartz tube, sealing, and then heating to $783 \mathrm{~K}$ in vacuum for $24 \mathrm{~h}$. Additional details of this synthesis were presented previously (16-18). The catalytic activity for the HDS of thiophene was measured in a simple flow reactor. Reaction temperatures ranged from 523 to $673 \mathrm{~K}$ and the pressure was maintained constant at $1 \mathrm{~atm}$. The powdered catalyst $(0.25-0.35 \mathrm{~g})$ was loaded into a quartz reactor and pretreated in flowing $\mathrm{He}(20$ $\mathrm{ml} / \mathrm{min}$ ) at 673 for $30 \mathrm{~min}$. The temperature was then lowered to the desired reaction temperature and the He flow was replaced by a $2.7 \%$ by volume thiophene in $\mathrm{H}_{2}$ ( 10 $\mathrm{ml} / \mathrm{min}$ ). The reactor effluent was analyzed by a gas chromatograph equipped with a thermal conductivity detector. Additional details may be found in the literature (16-18).

The samples to be examined in this study were chosen to include both high and low levels of promoter loadings. The $\mathrm{P} /(\mathrm{P} \times \mathrm{Mo})$ ratios (expressed in weight percent) of the samples ranged from 0.030 to 0.355 . The nomenclature used denotes the respective stoichiometries of the elemental starting materials used in the synthesis and has the form $\mathrm{P}_{2 x} \mathrm{Mo}_{1-x} \mathrm{~S}_{2}$ for the $\mathrm{Co}$ and $\mathrm{Fe}$ samples and 
$\mathrm{P}_{x} \mathrm{Mo}_{1-x} \mathrm{~S}_{2}$ for the $\mathrm{Ni}$ series. The specific stoichiometries of the promoted samples may be found in Table 1. A commercial sample (Katalco; with 12-16\% $\mathrm{MoO}_{3}, 2-5 \%$ $\mathrm{CoO}$, and the balance $\mathrm{Al}_{2} \mathrm{O}_{3}$ ) was also studied to provide an industrial benchmark against which the performance of our solidstate samples could be tested.

Chemisorption measurements were made with the pulse technique using a Quantasorb Model QS-17 sorption system. Powdered samples of catalyst (200-300 mg) were loaded into a glass U-tube cell. Prior to all chemisorption measurements, the samples were reduced in pure $\mathrm{H}_{2}$ at $573 \mathrm{~K}$ for a minimum of $8 \mathrm{~h}$. Although the reduction of HDS catalysts is generally a slow process, the work of Liu et al. (32) indicates that an 8 -h reduction period should be sufficient to entirely reduce our catalysts. The effect of different pretreatments on gas uptake was considered as an additional experimental parameter; however, studies have indicated (33) there was no noticeable change in adsorptive capacity after pretreatment with either $\mathrm{H}_{2}$ or $\mathrm{H}_{2} \mathrm{~S}$. After reduction, the sample was cooled ballistically to room temperature for $45 \mathrm{~min}$ and then placed in a $298 \mathrm{~K}$ constant temperature bath. A four-way valve allowed the pretreatment gas to be switched to He carrier gas without exposing the sample to air. Then, sequential pulses of chemisorption gas, $1 \mathrm{~cm}^{3}$ in volume, and consisting of either $9.98 \% \mathrm{O}_{2}$ in $\mathrm{He}$ or $9.96 \%$ $\mathrm{CO}$ in $\mathrm{He}$ were injected into the carrier gas stream. This apparatus was equipped with a thermal conductivity detector which sensed the breakthrough of $\mathrm{O}_{2}$ or $\mathrm{CO}$ once the catalyst was saturated with chemisorbed gas. The amount of $\mathrm{O}_{2}$ or $\mathrm{CO}$ retained on the catalyst was then easily calculated from a material balance, since the original amount injected into the system was known.

\section{RESULTS AND DISCUSSION}

Table 1 lists the catalyst samples with their respective $\mathrm{BET}$ surface areas and $\mathrm{CO}$ and $\mathrm{O}_{2}$ uptake capacities. Also included in this table are the data for the industrial HDS
TABLE 1

Surface Area and Adsorption Uptakes of Catalyst Samples

\begin{tabular}{lrcc}
\hline \multicolumn{1}{c}{ Sample } & $\begin{array}{c}\text { BET } \\
\left(\mathrm{m}^{2} / \mathrm{g}\right)\end{array}$ & $\begin{array}{c}\mathrm{O}_{2} \\
(\mu \mathrm{mole} / \mathrm{g})\end{array}$ & $\begin{array}{c}\mathrm{CO} \\
(\mu \mathrm{mole} / \mathrm{g})\end{array}$ \\
\hline $\mathrm{Co}_{0.05} \mathrm{Mo}_{0.975} \mathrm{~S}_{2}$ & 25.7 & 100.3 & - \\
$\mathrm{Co}_{0.1} \mathrm{Mo}_{0.95} \mathrm{~S}_{2}$ & 14.3 & 99.5 & 37.7 \\
$\mathrm{Co}_{0.5} \mathrm{Mo}_{0.75} \mathrm{~S}_{2}$ & 1.0 & 22.2 & - \\
$\mathrm{Co}_{0.6} \mathrm{Mo}_{0.7} \mathrm{~S}_{2}$ & 1.0 & 25.4 & - \\
$\mathrm{Fe}_{0.05} \mathrm{Mo}_{0.975} \mathrm{~S}_{2}$ & 14.0 & 57.2 & - \\
$\mathrm{Fe}_{0.1} \mathrm{Mo}_{0.95} \mathrm{~S}_{2}$ & 23.1 & 133.6 & 43.4 \\
$\mathrm{Fe}_{0.5} \mathrm{Mo}_{0.75} \mathrm{~S}_{2}$ & 5.9 & 128.6 & - \\
$\mathrm{Fe}_{0.6} \mathrm{Mo}_{0.7} \mathrm{~S}_{2}$ & 6.0 & 110.4 & - \\
$\mathrm{Ni}_{0.05} \mathrm{Mo}_{0.95} \mathrm{~S}_{2}$ & 15.1 & 120.2 & - \\
$\mathrm{Ni}_{0.1} \mathrm{Mo}_{0.9} \mathrm{~S}_{2}$ & 14.3 & 76.7 & 28.3 \\
$\mathrm{Ni}_{0.4} \mathrm{Mo}_{0.6} \mathrm{~S}_{2}$ & 1.4 & 32.6 & - \\
$\mathrm{Ni}_{0.6} \mathrm{Mo}_{0.4} \mathrm{~S}_{2}$ & 3.1 & 26.8 & - \\
$\mathrm{Katalco}$ & 156.3 & 160.1 & 65.7 \\
\hline
\end{tabular}

catalyst. It can be seen that within the Co and $\mathrm{Ni}$ promoter families those catalysts with a higher overall surface area displayed greater $\mathrm{O}_{2}$ or $\mathrm{CO}$ adsorption. However, for the $\mathrm{Fe}$ series, the lower surface area $\mathrm{Fe}_{0.5} \mathrm{Mo}_{0.75} \mathrm{~S}_{2}$ and $\mathrm{Fe}_{0.6} \mathrm{Mo}_{0.7} \mathrm{~S}_{2}$ samples showed a larger $\mathrm{O}_{2}$ capacity than would be expected judging from their BET areas. To explain this, we must refer to Ref. (18) and recall that these solid-state catalysts are not single-phase materials. In addition to the poorly crystalline $\mathrm{MoS}_{2}$-like phase detected by X-ray diffraction and electron diffraction, $\mathrm{FeS}_{2}$ was also formed in increasing quantities as the $\mathrm{Fe}$ concentration was raised in the synthesis charge. Hence, the greater $\mathrm{O}_{2}$ uptakes could be due to a preferential adsorption of the probe molecules by a secondary phase, such as $\mathrm{FeS}_{2}$, that would increase the amount of adsorbed gas for a given sample without providing a proportional increase in HDS activity. Further chemisorption experiments on iron sulfide phases are required to determine if this hypothesis is indeed correct.

In Figs. 1-3, turnover frequencies for HDS of thiophene are compared for the Co-, $\mathrm{Fe}-$, and Ni-promoted samples, plotting them in two different ways for each pro- 


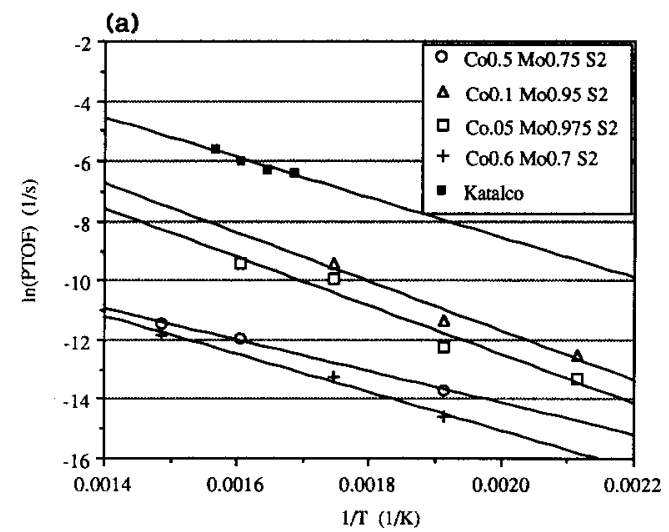

(b)

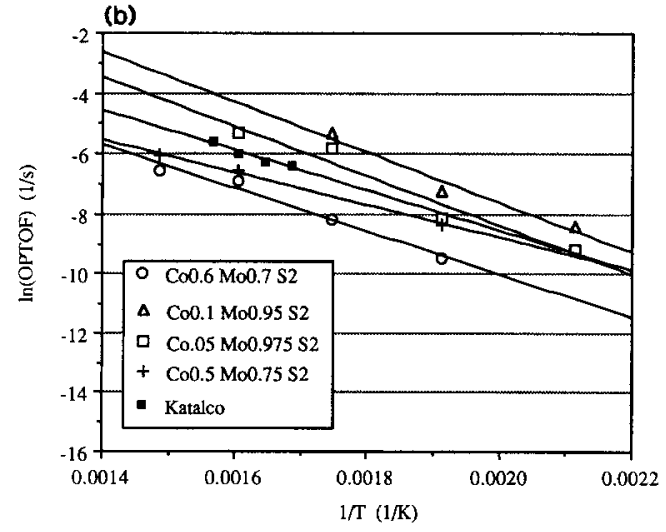

FIG. 1. Arrhenius plot for Co samples and Katalco. (a) Mo-normalized thiophene HDS turnover frequencies (PTOF) vs $1 / T$. (b) $\mathrm{O}_{2}$-normalized thiophene HDS turnover frequencies (OTOF) vs $1 / T$.

moter series. In Figs. 1a, 2a, and 3a, the natural $\log$ of the pseudo-turnover frequencies ( $\ln (\mathrm{PTOF}))$ has been plotted versus $1 / T$. The PTOF was defined as moles of thiophene converted per mole of Mo in the catalyst per second; hence, it may be thought of as a specific rate. The original purpose of the activity normalization as depicted in Figs. 1a, 2a, and $3 a$ was to compare these catalysts on a per Mo basis in hopes of determining which samples used Mo more efficiently in a catalytic sense. As can be seen from these graphs, the samples followed Arrhenius type behavior and provided experimental straight line fits with a corrected sum of squares greater than $93 \%$ in all cases.

Of interest in Fig. 1a was the large differ- ence in activity between the low loaded $\mathrm{Co}_{0.05} \mathrm{Mo}_{0.975} \mathrm{~S}_{2}$ and $\mathrm{Co}_{0.1} \mathrm{Mo}_{0.95} \mathrm{~S}_{2}$ catalysts and the high loaded $\mathrm{Co}_{0.5} \mathrm{Mo}_{0.75} \mathrm{~S}_{2}$ and $\mathrm{Co}_{0.6} \mathrm{Mo}_{0.7} \mathrm{~S}_{2}$ samples. Inspection of Table 1 shows that this lower activity was also accompanied by a decrease in $\mathrm{O}_{2}$ uptake. Similarly, for the Fe and Ni series, the more active samples (see Figs. $2 \mathrm{a}$ and $3 \mathrm{a}$ and Table 1) displayed the larger $\mathrm{O}_{2}$ capacities. However, it is interesting to note that the Fe samples did not follow the same $\mathrm{P} /(\mathrm{P}+$ $\mathrm{Mo}$ ) activity trend as the Co series did. The low loaded $\mathrm{Fe}_{0.05} \mathrm{Mo}_{0.975} \mathrm{~S}_{2}$ was not as active as the $\mathrm{Fe}_{0.5} \mathrm{Mo}_{0.75} \mathrm{~S}_{2}$ or $\mathrm{Fe}_{0.1} \mathrm{Mo}_{0.95} \mathrm{~S}_{2}$ samples, and this was reflected in the $\mathrm{O}_{2}$ chemisorption measurements. In addition, the $\mathrm{Fe}_{0.6} \mathrm{Mo}_{0.7} \mathrm{~S}_{2}$ sample adsorbed twice as much
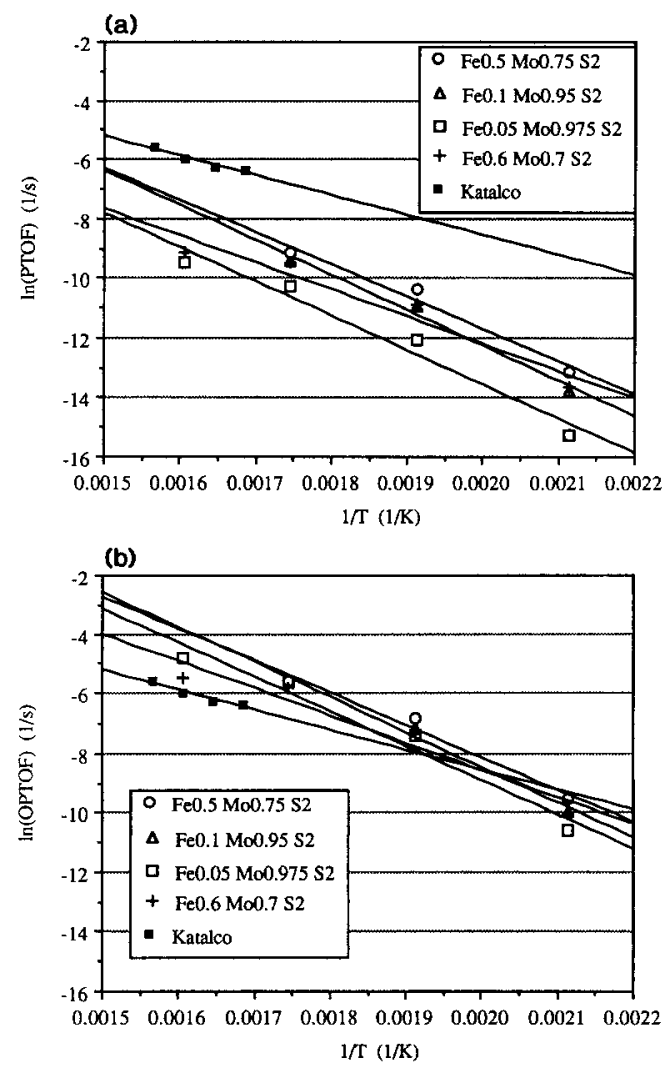

FIG. 2. Arrhenius plot for Fe samples and Katalco. (a) Mo-normalized thiophene HDS turnover frequencies (PTOF) vs $1 / T$. (b) $\mathrm{O}_{2}$-normalized thiophene $\mathrm{HDS}$ turnover frequencies (OTOF) vs $1 / T$. 

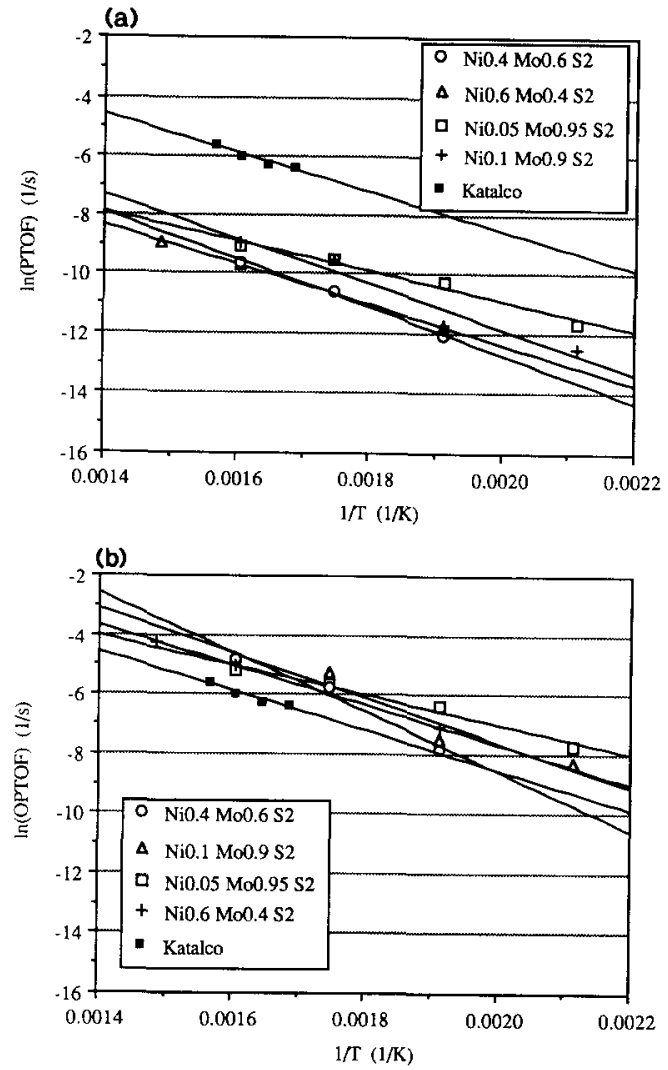

FIg. 3. Arrhenius plot for Ni samples and Katalco. (a) Mo-normalized thiophene HDS turnover frequencies (PTOF) vs $1 / T$. (b) $\mathrm{O}_{2}$-normalized thiophene HDS turnover frequencies (OTOF) vs $1 / T$.

$\mathrm{O}_{2}$ compared to $\mathrm{Fe}_{0.05} \mathrm{Mo}_{0.975} \mathrm{~S}_{2}$, but displayed similar activity. This could be due to the problem of preferential adsorption by a secondary phase mentioned earlier. The $\mathrm{Ni}$ catalysts behaved more like the Co-containing samples as the $\mathrm{Ni}_{0.05} \mathrm{Mo}_{0.95} \mathrm{~S}_{2}$ had the highest activity and adsorbed the most $\mathrm{O}_{2}$, and the other catalysts in this family showed decreasing activity and adsorption capacity with increasing $\mathrm{P} /(\mathrm{P}+\mathrm{Mo})$ values.

One final point to mention with regard to this set of figures is the high $\ln$ (PTOF) of the Katalco sample relative to the most active solid-state samples in all promoter families. The Katalco catalyst is supported on alumina and is only $12-16 \mathrm{wt} \% \mathrm{MoO}_{3}$; consequently, the majority of the Mo species pres- ent in the working catalysts are accessible to reactant molecules. Conversely, much of the Mo in the solid-state samples lies deep within the bulk of the material and is effectively unavailable for catalysis. It is not surprising then that normalizing the activity on a per mole of Mo basis favors the supported material.

In order to account for this inequity, the activity data were replotted in Figs. 1b, 2b, and $3 b$, this time normalizing them on a per $\mu$ mole of $\mathrm{O}_{2}$ adsorbed basis, showing $\mathrm{O}_{2}$ normalized pseudo-turnover frequencies (OPTOF) as a function of $1 / T$. As mentioned earlier, it is still debated whether $\mathrm{O}_{2}$ chemisorption provides a reliable measure of the catalytically active site due to the slow oxidation of the sample by the adsorbate. However, given the slow rate of oxidation and the fact that the adsorption was performed dynamically, $\mathrm{O}_{2}$ surface titration will yield a truer indication of the available sites for HDS than the total Mo content of the catalyst, especially for the bulk samples studied in this work, since much of the Mo is not a surface species. This normalization resulted in rates with units of "moles of thiophene converted per micromole of $\mathrm{O}_{2}$ adsorbed per second." If the above assumption proved valid, then the Arrhenius plots of $\mathrm{O}_{2}$ normalized pseudo-turnover frequencies should merge closer together. This would indicate that the chemisorption experiments were indeed titrating a majority of those sites responsible for activity, presumably the edge sites. If the Arrhenius plots remained unchanged or diverged to span a greater area, then it could safely be said that in this catalyst system, the $\mathrm{O}_{2}$ chemisorption did not successfully titrate those centers responsible for HDS activity.

It can be seen from Figs. 1b, 2b, and 3b that the data do indeed merge much closer together than when the rates were normalized on a per Mo basis. In addition, the industrial catalyst Katalco with the relatively larger adsorptive capacity now falls in the range of the solid-state model materials. As expected, the apparent activation 
energies do not change when $\ln (\mathrm{OPTOF})$ vs $1 / T$ are plotted, since the different normalization procedure could not possibly alter the reaction mechanism. What does change is the $y$-intercept or preexponential factor in the Arrhenius expression, which causes the lines of the graph to come closer together. This effect is most noticeable for the Fe series, where all the data now fall into a very narrow region. The Co series also merge appreciably; however, there was a larger spread in this data originally (see Fig. 1a). The $\mathrm{O}_{2}$ normalization of the $\mathrm{Ni}$ series also leads to a distinct compression of the Arrhenius plot at the higher temperatures. At lower temperatures (less than $473 \mathrm{~K}$ ) the spread mirrors that present in the original activity data (Fig. 3a) seen earlier. Based on these results it does indeed appear that the $\mathrm{O}_{2}$ chemisorption provides a meaningful measure of the catalytic area responsible for HDS activity.

From previous work on these model catalysts $(16-18)$ it is known that disordered sulfur-deficient $\operatorname{MoS}_{x}$ species played a key role in HDS catalysis, leading to enhanced activity compared to nearly defect-free $\mathrm{MoS}_{2}$. When promoters such as $\mathrm{Ni}, \mathrm{Fe}$, and $\mathrm{Co}$ were added, they were found to scavenge sulfur during catalyst synthesis, thereby facilitating the formation of disordered, sulfur-deficient $\mathrm{MoS}_{x}$. From the data presented here, it appears that $\mathrm{O}_{2}$ adsorption tracks the relative amounts of the catalytically active sulfur-deficient $\mathrm{MoS}_{x}$.

Only those samples with a promoter stoichiometry of $P_{0.1}$ have currently undergone $\mathrm{CO}$ adsorption experiments. As reported previously (13), $\mathrm{CO}$ adsorption was much slower than that of $\mathrm{O}_{2}$. A typical equilibration time for $\mathrm{CO}$ adsorption may have been up to 5 min for $\mathrm{CO}$, whereas $\mathrm{O}_{2}$ was usually equilibrated in less than $1 \mathrm{~min}$. Since we currently lack the $\mathrm{CO}$ data for all samples, it was not possible to compare the low- and high-activity Co series samples to determine if indeed the $\mathrm{CO}$ adsorption correlates as closely as the $\mathrm{O}_{2}$ measurements with HDS activity. However, HDS activity was nor-

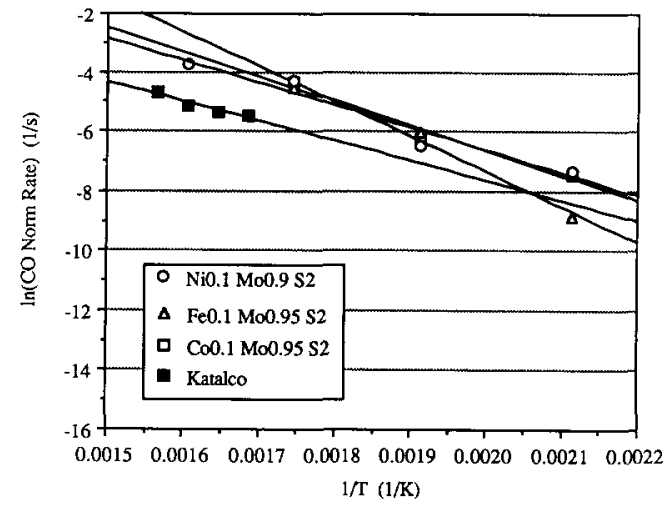

FIG. 4. CO-normalized Arrhenius plot for $(0.1)$ level promoted model catalysts and Katalco.

malized based on $\mathrm{CO}$ uptake for those samples with a promoter stoichiometry of 0.1 . Figure 4 depicts an Arrhenius plot using a similar normalization scheme employed with the $\mathrm{O}_{2}$ chemisorption data, only $\mathrm{CO}$ adsorption was now used as the normalizing factor. It can be seen that the data merge nicely at the higher temperatures, suggesting that $\mathrm{CO}$ is titrating those sites linked to activity. Below $473 \mathrm{~K}$ there is some spread present due primarily to the low activity of the Fe sample at lower temperature. All CO-normalized samples displayed HDS activities greater than the $\mathrm{CO}$-normalized Katalco sample, which again indicates that these model samples behave similarly to the industrial catalyst. Although the sample population in these $\mathrm{CO}$ studies was smaller than that of $\mathrm{O}_{2}$, these preliminary results are in keeping with the observations of others $(14,15)$, who were able to correlate HDS activity with $\mathrm{CO}$ chemisorption.

\section{CONCLUSIONS}

Based on these results, it appears that $\mathrm{O}_{2}$ chemisorption tracks and correlates quite well with the HDS activity of these solidstate model catalysts. Sharp endpoints in gas uptake were obtained for all samples tested, which would indicate that the problem of a slow surface oxidation encountered by other workers $(8,9)$ was not a factor in 
this case. Since the more active samples adsorbed increased amounts of $\mathrm{O}_{2}$, activity normalizations using $\mathrm{O}_{2}$ uptake resulted in a consolidation of the Arrhenius plots so that the individual data points merged into a narrow band on the plot. Oxygen activity normalizations also revealed that on a per mole of $\mathrm{O}_{2}$ basis, the model catalysts gave thiophene HDS turnover frequencies similar to those found on an industrial HDS catalyst, encouraging us to believe that these solid-state materials provide relevant models for HDS studies. It also appears that $\mathrm{CO}$ selectively adsorbs on the catalytic sites, although this judgement is not as clear as in the case of the $\mathrm{O}_{2}$ chemisorption since fewer samples were studied.

In these model catalysts sulfur-deficient $\operatorname{MoS}_{x}$ species play a key role in HDS catalysis. Promoters such as $\mathrm{Ni}, \mathrm{Fe}$, and $\mathrm{Co}$ mainly serve the purpose of scavenging sulfur during catalyst synthesis, thereby facilitating the creation of sulfur deficient $\mathrm{MoS}_{x}$. $\mathrm{O}_{2}$ adsorption, and to some extent also $\mathrm{CO}$ adsorption, appears to track the relative amounts of sulfur-deficient, nonstoichiometric $\mathrm{MoS}_{x}$ responsible for enhanced HDS activity. This correlation may help explain why $\mathrm{O}_{2}$ adsorption capacity can serve as a fast screening test for HDS activity.

\section{REFERENCES}

I. Burch, R., and Collins, A., Appl. Catal. 17, 273 (1985).

2. Topsøe, H., Candia, R., Topsøe, N., and Clausen, B. S., Bull. Soc. Chim. Belg. 93, 783 (1984).

3. Topsøe, H., and Clausen, B. S., Appl. Catal. 25, 273 (1986).

4. Bachelier, J., Duchet, J. C., and Cornet, D., Bull. Soc. Chim. Belg. 90, 1301 (1981).

5. Topsøe, H., Clausen, B. S., Topsøe, N., and Zeuthen, P., "Proceedings of the Catalysts in Petroleum Refining Conference," Kuwait, March 5-9, 1989.

6. Tauster, S. J., Pecoraro, T. A., and Chianelli, R. R., J. Catal. 63, 515 (1980).

7. Bachelier, J., Duchet, J. C., and Cornet, D., J. Phys. Chem. 84, 1925 (1980).

8. Zmierczak, W., Murali Dhar, G., and Massoth, F. E., J. Catal. 77, 432 (1982).

9. Daage, M., and Chianelli, R. R., Private communi- cation cited in Catal. Rev. Sci. Eng. 31(1,2), 1 (1989).

10. Agudo, A., Llambias, F. J., Tascon, J. M. D., and Fierro, J. L. G., Bull. Soc. Chim. Belg. 93(8, 9) 719 (1984).

11. Millman, W. S., Bartholomew, C. H., and Richardson, R. L., J. Catal. 90, 10 (1984).

12. Bodrero, T., and Bartholomew, C. H., J. Catal. 84, 145 (1983).

13. Bachelier, J., Duchet, J. C, and Cornet, D., J. Catal. 87, 283 (1984).

14. Bachelier, J., Tilliette, M. J., Cornac, M., Duchet, J. C., Lavalley, J. C., and Cornet, D., Bull. Soc. Chim. Belg. 93(8, 9), 743 (1984).

15. Bachelier, J., Duchet, J. C., and Cornet, D., Bull. Soc. Chim. Belg. 90, 1301

16. Villa-Garcia, M. A., Lindner, J., Sachdev, A., and Schwank, J. Catal. 119, 388 (1989).

17. Lindner, J., Sachdev, A., Villa-Garcia, M. A., and Schwank, J. Catal. 120, 487 (1989).

18. Villa-Garcia, M. A., Lindner, J., Sachdev, A., and Schwank, Appl. Catal. 56, 281 (1989).

19. Lipsch, J. M. J. G., and Schuit, G. C. A., J. Catal. 15, 179 (1969).

20. Gates, B. C., Katzer, J. R., and Schuit, G. C. A., in "Chemistry of Catalytic Processes," Chap. 5. McGraw-Hill, New York, 1979.

21. Massoth, F. E., J. Catal. 36, 154 (1975).

22. Voorhoeve, R. J. H., and Stuiver, J. C. M. J. Catal. 23, 243 (1971).

23. Farragher, A. L., and Cossee, P., in "Proceedings, 5th International Congress on Catalysis, Palm Beach, 1972"' (J. W. Hightower, Ed.), p. 1301. North-Holland, Amsterdam, 1973.

24. Hagenbach, G., Courty, P., and Delmon, B., J. Catal. 23, 295 (1971).

25. Delmon, B., Am. Chem. Soc. Div. Petrol. Chem. Prepr. 22, 503 (1977).

26. Hagenbach, G., Courty, P., and Delmon, B. J. Catal. 31, 264 (1973).

27. Topsøe, H., Clausen, B. S., Candia, R., Wivel, C., and Mørup, S., J. Catal. 68, 433 (1981).

28. Wivel, C., Candia, R., Clausen, B. S., Mørup, S., and Topsфe, H., J. Catal. 68, 453 (1981).

29. Vissers, J. P. R., de Beer, V. H. J., and Prins, R., J. Chem. Soc. Faraday Trans. 1 83, 2145 (1987).

30. van der Kran, A. M., Crajé, M. W. J., Gerkema, E., Ramselaar, W. L. T. M., and de Beer, V. H. J., Appl. Catal. 39, L7 (1988).

31. van der Kran, A. M., Crajé, M. W. J., Gerkema, E., Ramselaar, W. L. T. M., and de Beer, V. H. J., Hyperfine Interact. 46, 567 (1989).

32. Liu, H. C., Yuan, L., and Weller, S. W., J. Catal. 61, 282 (1980).

33. Milliman, W. S., Bartholomew, C. H., and Richardson, R. L., J. Catal. 90, 10 (1984). 